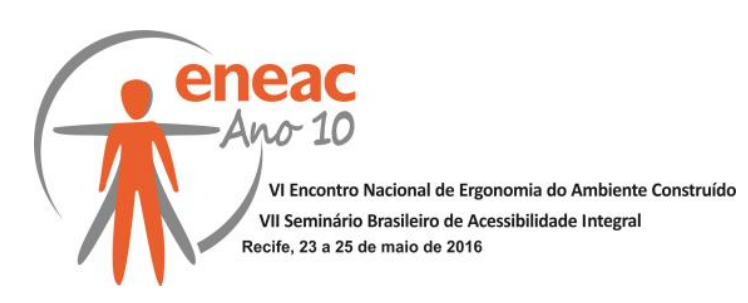

\title{
RETRATO DAS CONDIÇÕES DE ACESSIBILIDADE DOS CAMPI DA UFPB
}

\author{
OLIVEIRA, Camila Correia de (1); \\ LAURENTINO, Rodrigo dos Santos (2) \\ COSTA, Angelina Dias Leão (3)
}

(1) Universidade Federal da Paraíba, Aluna de graduação em Arquitetura e Urbanismo e-mail:camilacorreiaoliveira2@gmail.com

(2) Universidade Federal da Paraíba, Aluno de graduação em Arquitetura e Urbanismo e-mail:rodrigo.s laurentino@hotmail.com

(3) Universidade Federal da Paraíba, Prof. ${ }^{a}$ Dr. ${ }^{-}$do DA e do Programa de Pós-graduação em Arquitetura e Urbanismo

e-mail: angelinadlcosta@yahoo.com.br

\begin{abstract}
RESUMO
A falta de aplicação das normas de acessibilidade em instituições de uso público como as universidades, contribui fortemente para a exclusão social visto que essas abrigam função democrática e de livre acesso. Com base na legislação vigente, foi elaborado como um 'retrato' da situação atual nos cinco Campi da UFPB, a fim de identificar os problemas existentes, como primeiro passo para adequar esses locais a recepção de todos, sem exceções.
\end{abstract}

Palavras chave: acessibilidade; universidades; exclusão social; livre acesso.

\begin{abstract}
The lack of application of the accessibility standards in public institutions such as universities, contributes substantially to social exclusion, since they have democratic and free access function. Based on current legislation, it was elaborated as a 'portrait' of the current situation in the five campuses of UFPB in order to identify the problems, as a first step to adapt those places to be enjoyed by everyone, without exceptions.
\end{abstract}

Keywords: accessibility; universities; social exclusion; free access

\section{INTRODUÇÃO}

Enquanto instituição multidisciplinar, a Universidade é um lugar democrático e diversificado que deve permitir livre acesso a seus usuários independentemente de sexo, idade, cultura, destreza, força, dentre outras características que nos difere e individualiza enquanto seres humanos (VERGARA, et al, 2009). Uma vez que essas instituições de ensino abrigam a função democrática e de livre acesso, esses espaços necessitam estar adequados a uma gama de diferentes usuários que os frequentam, provendo a todos, 


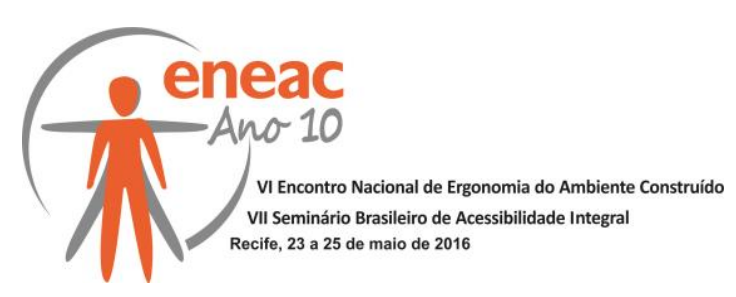

condições para a utilização e vivência nos campi, com o mínimo de qualidade e eficiência. Do mesmo modo, por seu caráter educacional e sua vocação inovadora, as universidades devem servir de parâmetro para a sociedade, seja na questão da acessibilidade ou de qualquer outro componente, haja vista a importância que esses espaços possuem para a sociedade.

A lei $N^{\circ}$ 13. 146, sancionada em 6 de julho de 2015 define acessibilidade como possibilidade e condição de alcance, percepção e entendimento para utilização, com segurança de espaços, mobiliários, equipamentos urbanos, edificações, transportes, informação e comunicação, inclusive seus sistemas e tecnologias, bem como outros serviços e instalações abertos ao público, de uso público ou privado de uso coletivo, tanto na zona urbana como na rural, por pessoa com deficiência ou mobilidade reduzida. Ainda sobre o tema a lei discorre que a acessibilidade é direito que garante a pessoa com deficiência ou mobilidade reduzida viver de forma independente e exercer seus direitos de cidadania e de participação social. (BRASIL, 2015). Com isso, para o cumprimento pleno dessa lei é preciso eliminar todas as barreiras, sejam elas físicas ou atitudinais, que impedem essas pessoas de viverem de forma independente.

Segundo Sassaki 2010, a sociedade, como um todo, atravessou várias fases no que diz respeito a práticas sociais. Partindo da exclusão para o atendimento segregado e recentemente, para a modificação dos sistemas sociais gerais tem adotado a filosofia da inclusão social. O que não quer dizer que a sociedade deixou de praticar a exclusão ou a segregação, entretanto, hoje há uma preocupação gradativa em incluir as pessoas com deficiência. $E$ no que se refere aos campi universitários essa preocupação não deve em nem pode ser diferente.

Ainda sobre o conceito de inclusão Sassaki 2010 comenta que o processo de inclusão contribui para a formação de um novo corpo social através das transformações, sejam elas pequenas ou grandes, nos ambientes físicos e na maneira de pensar de todas as pessoas o que não exclui a própria pessoa com deficiência.

Logo, percebe-se a importância deste trabalho como um "retrato" da situação atual nos cinco Campi da UFPB para identificar os problemas de acessibilidade existentes, como primeiro passo para adequar essa instituição a recepção de todos, sem exceções.

Por isso, como objetivo propôs-se o levantamento das condições de acessibilidade, um retrato que procurasse englobar os todos os Campi da Universidade Federal da Paraíba, que são: Campus I, na cidade de João Pessoa, onde neste foi selecionado o núcleo de Direito em Santa Rita, visto que essa é uma edificação relativamente nova e diferente da sede não passou por nenhuma avaliação relacionada com a acessibilidade, o Campus II, na cidade de Areia, o Campus III, na cidade de Bananeiras, o Campus IV, nas cidades de Mamanguape e Rio Tinto e o campus V em Mangabeira.

\section{METODOLOGIA}

A UFPB com sua estrutura multicampi, atua em seis cidades da Paraíba, possuindo sua sede, o campus I, no Bairro Castelo Branco, na cidade de João Pessoa, mais com um núcleo do curso de direito recém-inaugurado na cidade de Santa Rita, além disso, João Pessoa abriga também o Campus V no bairro de Mangabeira, os campi II e III respectivamente, em Areia e Bananeiras e o campus IV que está dividido em dois centros nas cidades de Rio Tinto e Mamanguape.

Este diagnóstico foi realizado como parte das ações propostas pelo Grupo de trabalho acessibilidade arquitetônica (GT-AA), um dos grupos de trabalho do comitê de Inclusão acessibilidade (CIA) da UFPB. Os campi abordados foram escolhidos como primeira ação de reconhecimento da situação de acessibilidade desses campi a fim de expandir os trabalhos para além da sede do Campus I, onde o grupo focava suas ações. 


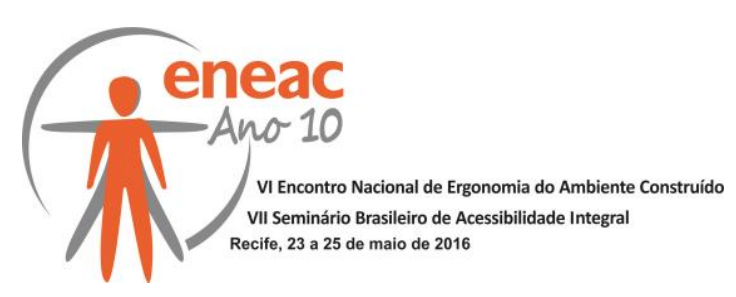

A metodologia utilizada para a realização do 'retrato' foi estruturada com a finalidade de proporcionar um padrão para os levantamentos realizados nas diferentes localidades em que estão situados os diversos Campus da Universidade Federal da Paraíba. Este padrão, foi baseado na escolha de um trajeto em comum, que atenda uma diversidade maior de pessoas, por isso o percurso estabelecido para análise foi das imediações do portão de acesso até a utilização dos serviços do Restaurante Universitário e da Biblioteca.

Inicialmente, foi realizada uma coleta sistemática de dados, documentos, informações, de projetos e mapas disponibilizados pela Prefeitura do Campus, que possibilitaram um reconhecimento geral das áreas de estudo, com exceção dos Campi de Areia e Bananeiras que na prefeitura não constavam os mapas. Em seguida, foi criado um roteiro de avaliação para registrar as barreiras arquitetônicas presentes no percurso realizado em cada campus, desde à sua chegada no Campus até o Restaurante Universitário e a Biblioteca. Principiou-se a observar o percurso pela área externa dos Campi, notando os abrigos de ônibus mais próximos e os acessos a eles. Posteriormente, a área dos estacionamentos e, dependendo da localização dos serviços escolhidos, define-se a necessidade de avaliar uma rota interna.

Quanto aos procedimentos técnicos adotados, foram selecionados a visita in loco e a técnica de pesquisa walkthrough, que consiste em conversas informais com os usuários do local para obter informações sobre os caminhos utilizados identificando as condições dos percursos por meio de coletas de dados, croquis e fotografias (REINGHANTZ, et al, 2008).

Como suporte material para realização desse trabalho, fez-se uso de câmera fotográfica como instrumento para registro da situação encontrada, prancheta para escrever observações importantes sobre os espaços avaliados bem como, para desenho de croquis e trena com o objetivo de fazer as mensurações necessárias nos trajetos. Ao passo que o levantamento de cada Campus era concluído ocorriam as análises dos dados e sistematização das informações.

\section{RESULTADOS}

O diagnóstico da situação de acessibilidade encontrada nos campi, foi obtido a partir do confronto das situações encontradas com a NBR 9050:2004, mas visto que essa norma foi atualizada recentemente, para que a análise não ficasse desatualizada, passamos a observar os parâmetros da NBR 9050:2015.

\subsection{Campus I - Santa Rita - Centro De Ciências Jurídicas (CCJ))}

Constitui-se uma extensão do Centro de Ciências Jurídicas, localizada no município de Santa Rita (região metropolitana de João Pessoa), conhecida como Departamento de Ciências Jurídicas (DCJ). Trata-se de uma construção recente, que passou a abrigar o curso de direito a partir de 2014. Oferece 12 salas de aula, 02 blocos de administração e ambiente de professores, além de auditório, biblioteca e área de convivência.

O trajeto avaliado no Centro de Santa Rita foi realizado a partir do abrigo de ônibus, avaliando os dois portões de entrada que ficam localizados lado a lado e o estacionamento, sendo necessária a inclusão de uma rota interna pois a biblioteca localiza-se dentro do bloco, a chegada até ela pode ser realizada através dos dois primeiros blocos possuindo o primeiro apenas uma escada e o segundo é possível acessá-lo por uma rampa, sendo o percurso avaliado pela rampa. Posteriormente, percorreu-se o trajeto como opção para quem chega de carro desde a área externa onde se localizam as vagas especiais até 0 acesso para a biblioteca (Figura 1 tabela 1). 


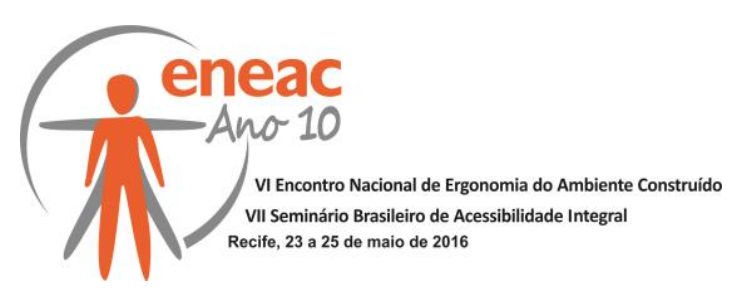

Figura 1 - Planta baixa do Campus I núcleo direito em Santa Rita, com destaque a rampa da entrada principal (b); acesso principal c); rampa acesso aos blocos de aula d).
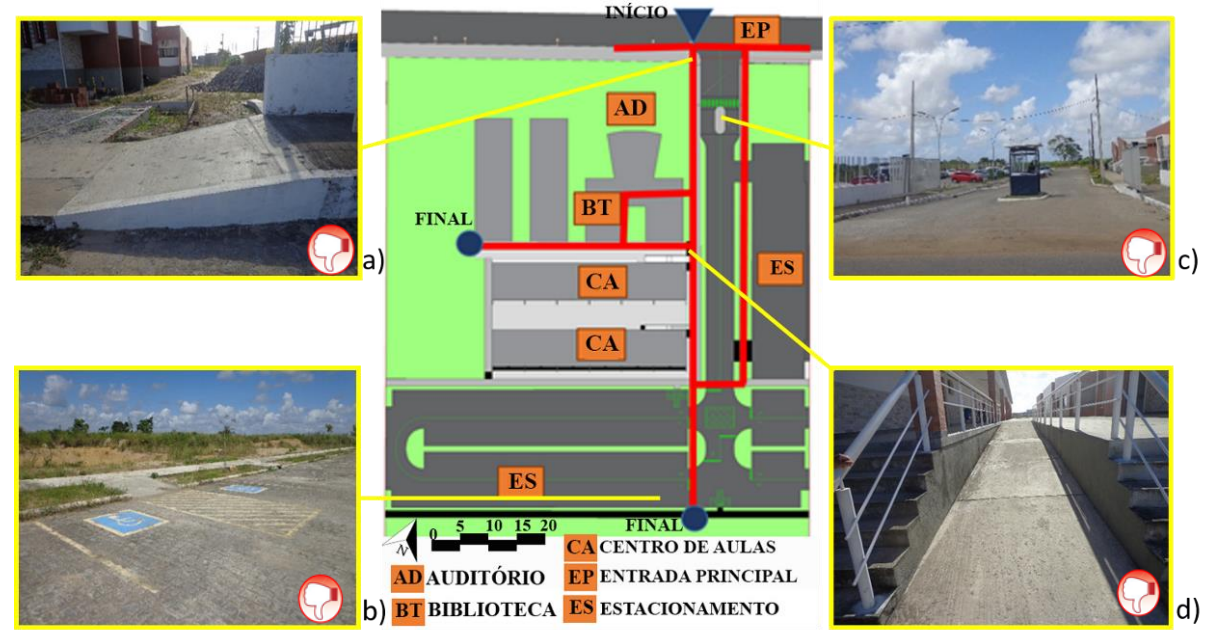

Fonte: Prefeitura Universitária. Editado pelos autores, 2015.

\section{Tabela 1- situação de acessibilidade encontrada no núcleo de direito}

\begin{tabular}{|c|c|}
\hline SITUAÇÃO ENCONTRADA & AVALIAÇÃO \\
\hline $\begin{array}{l}\text { Rampa após o portão a) - Após o portão de entrada } \\
\text { para pedestres há a presença de uma rampa que } \\
\text { possui } 8,97 \% \text { de inclinação }\end{array}$ & $\begin{array}{l}\text { A NBR 9050/2015 recomenda que a inclinação } \\
\text { longitudinal das áreas de circulação exclusivas de } \\
\text { pedestres seja no máximo de } 8,33 \% \text {, sendo a } \\
\text { situação encontrada passível de adequação. }\end{array}$ \\
\hline $\begin{array}{l}\text { Estacionamento b) - Há quatro vagas acessíveis } \\
\text { sinalizadas e demarcadas com o símbolo } \\
\text { internacional de acesso e com as dimensões } \\
\text { recomendadas pela norma. Porém, duas } \\
\text { encontram-se desconectadas dos blocos de aulas. }\end{array}$ & $\begin{array}{l}\text { Para facilitar o acesso as vagas reservadas, faz-se } \\
\text { necessário reposicionar para próximo dos acessos da } \\
\text { instituição as duas vagas que estão distantes dos } \\
\text { blocos. }\end{array}$ \\
\hline $\begin{array}{l}\text { Entrada principal c) - A dimensão da calçada do } \\
\text { entorno do campus possui } 2 \text { metros de largura, } \\
\text { piso regular e a ausência de piso tátil de } \\
\text { sinalização. }\end{array}$ & $\begin{array}{l}\text { Para torna-se acessível, a calçada da instituição } \\
\text { deve possuir piso tátil de sinalização e alerta para } \\
\text { informar e direcional a pessoa com deficiência visual } \\
\text { ou com baixa visão. }\end{array}$ \\
\hline $\begin{array}{l}\text { Rampa de acesso a biblioteca d) - A rampa não } \\
\text { possui nenhuma sinalização que indique a } \\
\text { presença de uma rampa. }\end{array}$ & $\begin{array}{l}\text { A inserção de sinalização tátil direcional e de alerta é } \\
\text { passível de reverter a situação encontrada. }\end{array}$ \\
\hline
\end{tabular}

Fonte: Elaborada pelos autores, 2015

\subsection{Campus II - Centro De Ciências Agrárias (CCA)}

Implantado em um terreno com topografia acidentada, o Campus é dotado de prédios antigos e outros edificados recentemente, que ainda não se encontram em uso. Com sua estrutura atendendo a diversos laboratórios, salas de aula, restaurante, biblioteca, centro de convivência, quadra poliesportiva, residências universitárias, campo de futebol, centro administrativo e ambientes dos professores, além de abrigar dentro dos seus limites o Museu do Brejo Paraibano.

Com as suas edificações locadas em variadas alturas no terreno, foi observado que o Campus possui cinco acessos distintos. Entretanto, para a realização deste diagnóstico, foi analisado a rota que se inicia na entrada principal da instituição, localizada na rodovia 


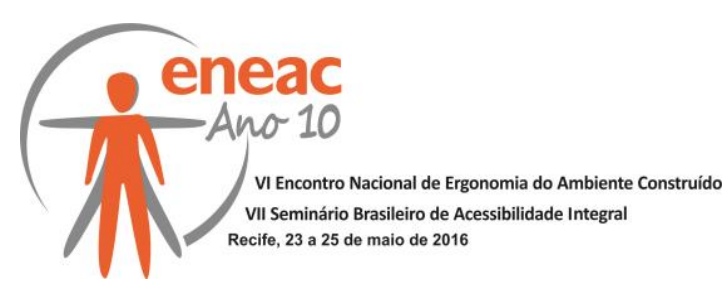

PB-079, sendo a mais utilizada pelos estudantes e a que permite um percurso mais direto para o acesso ao restaurante universitário e a biblioteca, ainda que apresente uma descida íngreme ao longo do trajeto (Figura 2, tabela 2).

Figura 2 - mapa do Campus II Centro De Ciências Agrárias com destaque para o acesso a biblioteca a); calçada apenas em um lado da via b); desnível logo após a portaria c); estacionamento sem sinalização em cima do passeio d); e acesso ao RU e).

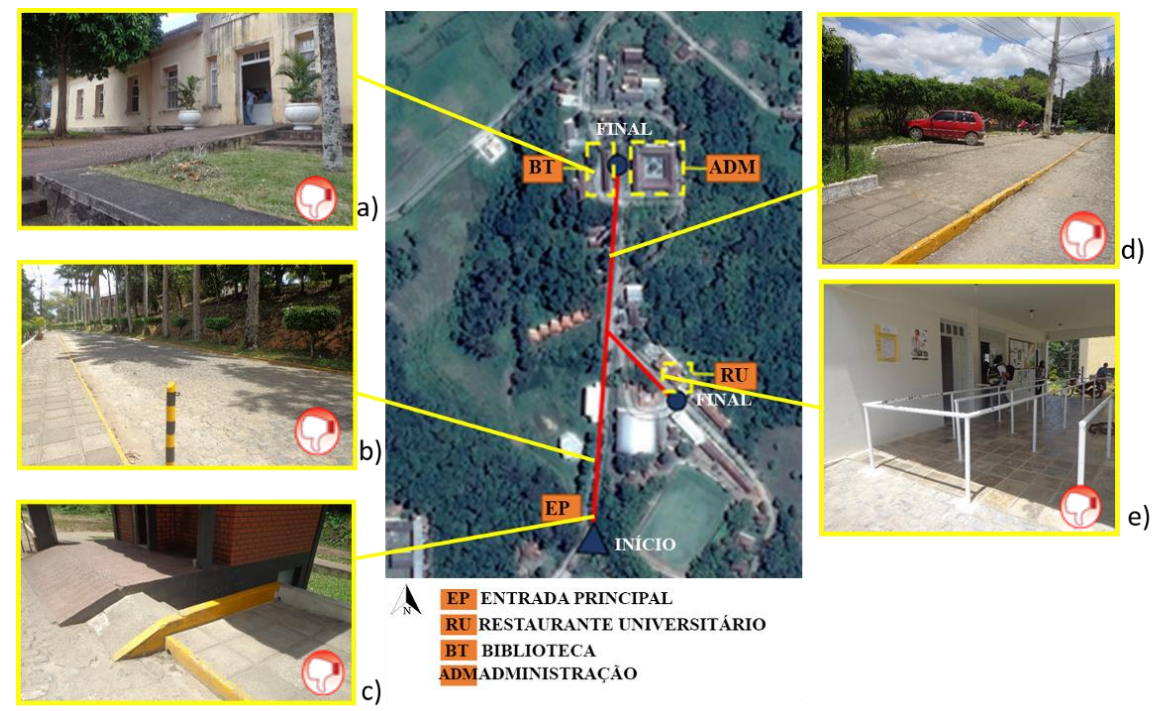

Fonte: Prefeitura Universitária. Editado pelos autores, 2015.

\section{Tabela 2- situação de acessibilidade encontrada no Centro De Ciências Agrárias}

\section{SITUAÇÃO ENCONTRADA}

Acesso a biblioteca a) - Para chegar na biblioteca é necessário continuar a rota interna iniciada no portão de entrada e enfrentar uma descida íngreme, não existindo faixa elevada ou rebaixamento de calçada no trajeto. Para entrar na edificação, passa-se por rampa com $5,52 \%$ de inclinação, atendendo ao que é previsto na NBR 9050.

Passeio em apenas um lado da via b) - Possui superfície irregular, sem piso tátil de alerta e direcional ou rebaixamento do meio fio, algo notado em todo o Campus.

Rampa após a entrada principal c) - Após o portão da guarita, na calçada o percurso é interrompido pela existência do início da escadaria que dá acesso aos blocos que ficam em outro nível topográfico.

Estacionamento na calçada d) - Ao longo da calçada surge um estacionamento abruptamente, sem apresentar qualquer tipo de sinalização.
O terreno íngreme é um empecilho irreversível para quem utiliza a cadeira de roda, mas faz-se necessário a inserção de piso tátil direcional e de alerta, bem como calçada elevada.

Para torna-lo acessível, é necessário a inserção de piso tátil direcional e de alerta, além de rebaixar o meio fio.

Faz-se necessário deixar o passeio livre de obstáculo e com o piso regular e nivelado.

Deve haver um passeio que permita contornar o estacionamento com segurança, sendo preciso também inserir sinalização direcional e de alerta.

A passagem da cadeira de roda deve ser desobstruída e com largura mínima de 


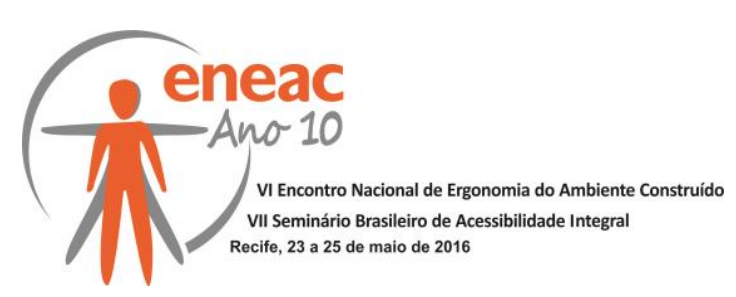

organizar a fila, mas com largura de $0,75 \mathrm{~m}$, elas impossibilitando a passagem de usuários de cadeiras de rodas.

Fonte: Elaborada pelos autores, 2015

\subsection{Campus III - Centro De Ciências Humanas Sociais e Agrárias (CCHSA)}

Localizados nos municípios de Bananeiras e Solânea, hoje, o Campus III da UFPB oferta os cursos de Graduação de Bacharelado em Agroindústria, Licenciatura em Ciências Agrárias, Bacharelado em Administração, Pedagogia e Agroecologia.

Quanto as características, a maioria das edificações locadas no Campus possuem caráter histórico, porém, há algumas edificações mais atuais. Como estrutura principal o campus apresenta salas de aulas, laboratórios, ambientes dos professores, administração, restaurante universitário, biblioteca, residência universitária e centro de vivência. Em relação ao terreno que está implantado o Campus apresenta uma topografia bastante acentuada.

O trajeto começou, a partir do portão de entrada da instituição que fica situado na parte mais baixa do terreno fazendo o percurso do pedestre até a biblioteca e o restaurante universitário, que se localizam na parte intermediária. $\mathrm{O}$ acesso à ambos pode ser realizado através de dois caminhos sendo o percurso escolhido passando pela área onde estão localizados alguns laboratórios. Em relação ao reconhecimento da área foi possível ir até a parte localizada em Solânea, sendo necessário subir uma ladeira bem íngreme, percurso feito a pé por alguns estudantes, mas pode ser realizado pelo ônibus que circula; nessa parte do CCHSA, também há uma biblioteca, por isso, observamos e fotografamos um pouco dessa área.

A situação desse Campus foi apresentada na tabela abaixo (tabela 3), visto que o Campus não possui planta baixa geral, além disso, não foi possível conseguir uma vista de satélite pois havia uma nuvem que encobria a localização do Campus e suas edificações.

\section{Tabela 3 - ilustração da situação encontrada no Centro De Ciências Humanas Sociais e Agrárias}

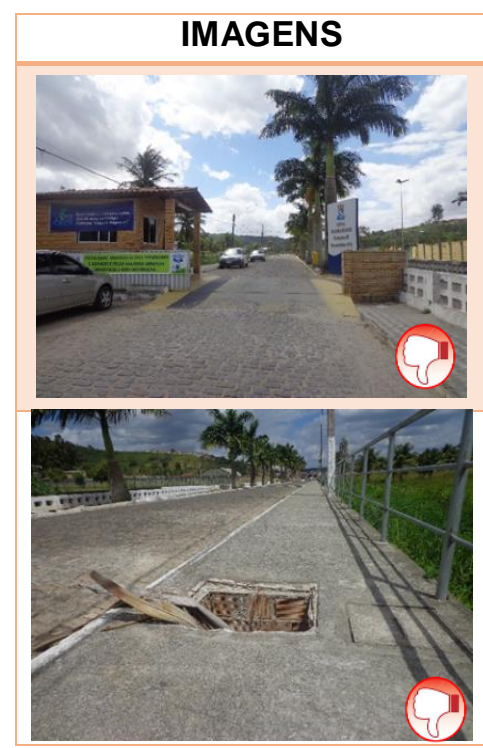

\section{SITUAÇÃO ENCONTRADA}

Entrada principal - A calçada encontra-se deteriorada e sem a presença de piso tátil direcional ou linha guia na sua extensão e para continuar o trajeto faz-se necessário atravessar uma lombada, por que a calçada termina no muro do portão de acesso ao campus.

\section{AVALIAÇÃO}

A calçada deve ser desobstruída de obstáculos e conter sinalização tátil direcional e de alerta para torna-se acessível de acordo com a NBR 9050/2015.

Caixas de inspeção sem tampas O passeio encontra-se em péssimas condições, o piso está deteriorado e ao longo do percurso foram identificados vários desníveis causados por tampas de caixa de inspeção, sendo também ausente em algumas partes do trajeto.
A calçada deve ter o piso regular e com as tampas das caixas de inspeção das

concessionárias locadas a nível do passeio. 


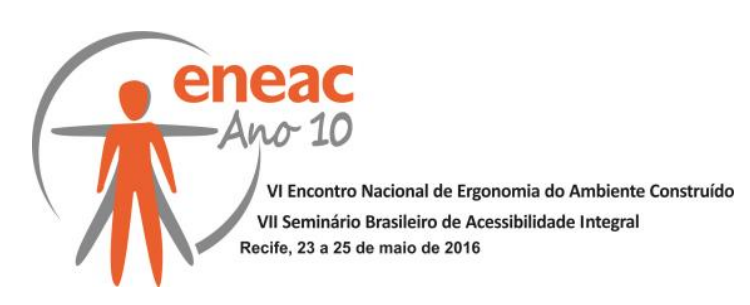

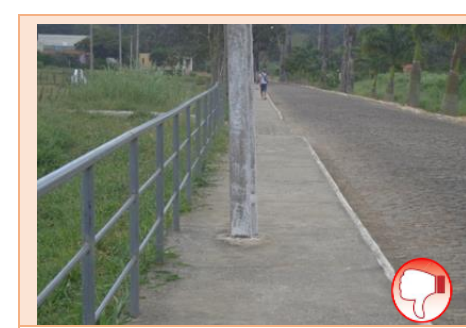

Obstáculos no passeio - Ao longo do caminho também registramos a presença de mobiliário, que ocupa boa parte da faixa livre deixando à apenas com a dimensão de $0,70 \mathrm{~m}$ metros.
Como recomendado pela norma, o passeio não deve ter obstáculos e ter no mínimo 0,90m de largura.

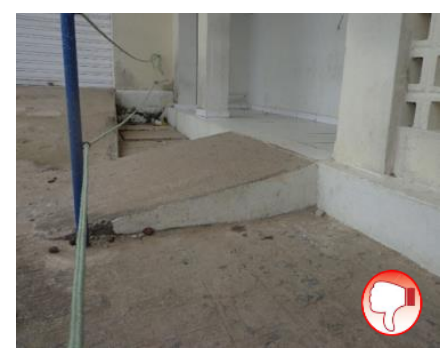

Restaurante universitário - Há desníveis de 0,6m nas entradas e nas portas, na parte onde se forma a fila para entrar no interior da edificação. Com relação a porta secundária do restaurante há uma rampa com aproximadamente $30 \%$ de inclinação, um obstáculo para os usuários.
Os desníveis devem vencidos por rampas com inclinação mínima de $8,33 \%$ de inclinação, como determina a NBR 9050/2015.

Fonte: Elaborada pelos autores, 2015

\subsection{Campus IV - Centro De Ciências Aplicadas e Educação (CCAE) - Rio Tinto}

Criado em 2005 pela UFPB, a partir do Programa de Apoio a Planos de Reestruturação e Expansão das Universidades Federais (REUNI), o Centro de Ciências Aplicadas e Educação abrange o Litoral Norte do Estado da Paraíba ao se estabelecer nos municípios de Mamanguape e Rio Tinto.

A extensão do Campus que está sediado em Rio Tinto oferece os cursos de graduação em Sistema de Informação, Ecologia, Design, Ciência da Computação, Matemática e Antropologia. Embora edificado no terreno de uma fábrica antiga, a maior parte das edificações da instituição são relativamente novas e apresentam uma estrutura composta por salas de aulas, laboratórios, ambientes dos professores, centro de convivência, restaurante, residências universitárias e biblioteca, centro administrativo e área poliesportiva.

O percurso realizado no Campus de Rio Tinto foi iniciado no único acesso de entrada da instituição, que é utilizada conjuntamente por veículos e pedestres, onde foi observado o trecho externo existente para os pedestres e a guarita de entrada. Em seguida, foi analisado o caminho mais usual para chegar a biblioteca e ao restaurante da instituição, tanto para que utilizada a calçada como para quem se desloca desde o estacionamento principal do campus (Figura 3 tabelas 4 ).

Figura 3: Planta baixa do Campus IV com destaque Calçada da entrada principal (a); poste locado na faixa de serviço, ausência de rampa (b); rampa do restaurante universitário (c); acesso centro de vivencia (d); e estacionamento. (e) 

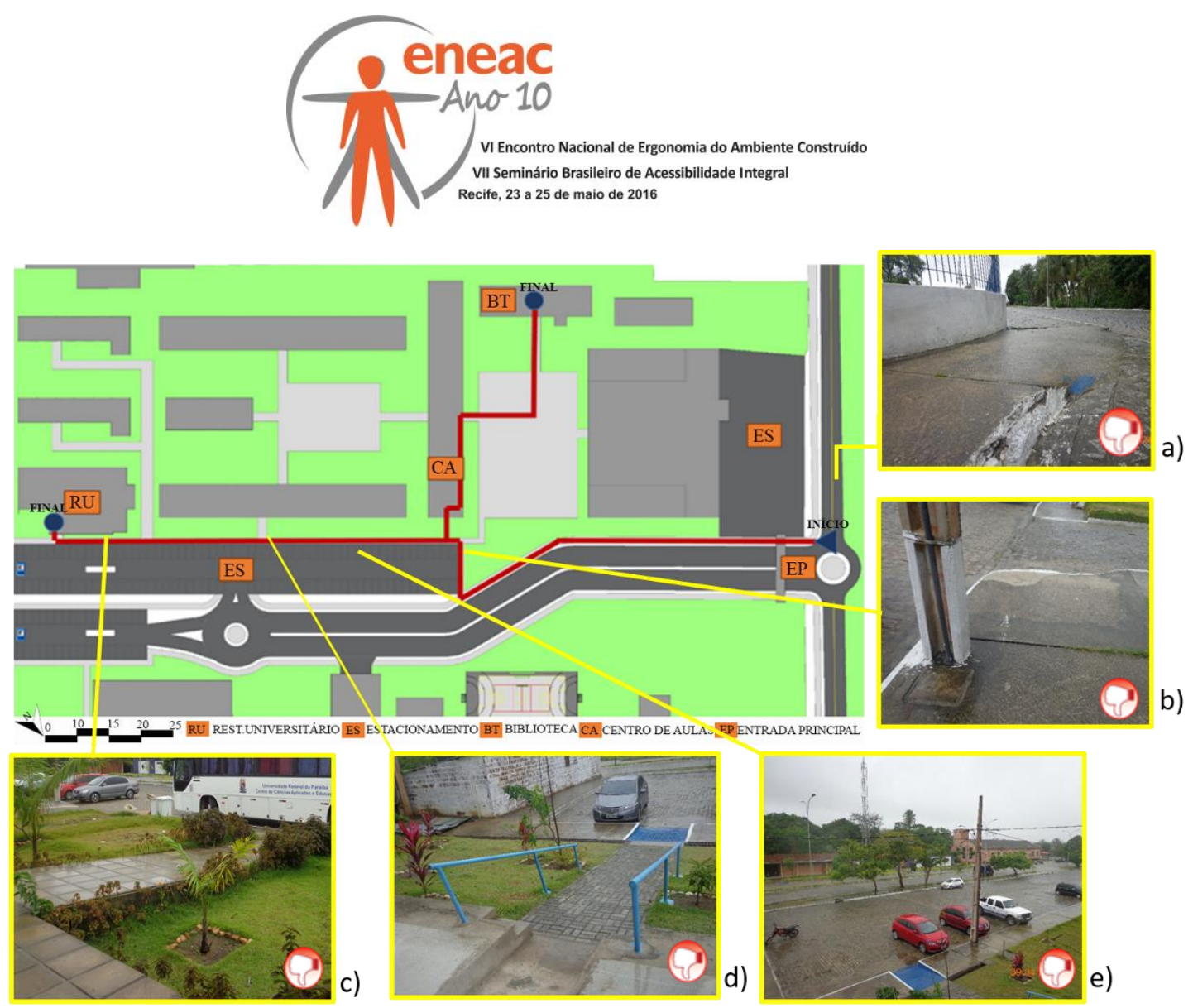

Fonte: Prefeitura Universitária. Editado pelos autores, 2015.

\section{Tabela 4 - situação de acessibilidade encontrada no CCAE - Rio Tinto}

\begin{tabular}{|c|}
\hline ÃO ENCONTRADA \\
\hline $\begin{array}{l}\text { Entrada principal a) - A circulação externa } \\
\text { apresenta um rebaixamento no meio fio, mas } \\
\text { encontra-se desalinhada, sem sinalização e sem as } \\
\text { dimensões estabelecidas pela NBR } 9050 \text {, além do } \\
\text { piso apresentar superfície irregular. }\end{array}$ \\
\hline $\begin{array}{l}\text { Ausência de rampas b). No percurso há vários } \\
\text { trechos que não possui rampas para vencer os } \\
\text { desníveis das calçadas elevadas. }\end{array}$ \\
\hline $\begin{array}{l}\text { Rampa em frente ao restaurante c) - Em frente ao } \\
\text { restaurante, há uma rampa com } 13,56 \% \text { de } \\
\text { inclinação, superior ao estabelecido pela NBR } 9050 \text {, } \\
\text { além de apresentar um piso com superfície } \\
\text { trepidante. }\end{array}$ \\
\hline $\begin{array}{l}\text { Rampa de acesso ao centro de vivencias d) - Pela } \\
\text { área de vivência acessa-se o bloco que funciona } \\
\text { como salas de aulas e ambientes para os } \\
\text { professores, mas é necessário passar por uma } \\
\text { rampa com } 14,16 \% \text { de inclinação e corrimão mal } \\
\text { dimensionado, ambos não correspondendo ao } \\
\text { previsto na NBR } 9050\end{array}$ \\
\hline
\end{tabular}

Estacionamento e) - O estacionamento e os blocos das edificações ficam em local plano e possuem dimensões distintas, fora das medidas determinadas pela norma em alguns casos, enquanto nos estacionamentos não foram encontradas vagas exclusivas para pessoas com deficiência
Faz-se necessário adequar a calçada rebaixada ao que é recomendado pela NBR 9050/ 2015 e dotá-la de sinalização e piso tátil direcional e de alerta.

Faz-se necessário dotar o passeio com piso regular e sem obstáculos, como espaçamento mínimo de $1,20 \mathrm{~m}$.

A NBR 9050/2015 recomenda inclinação de rampa com no máximo $8,33 \%$ de inclinação, além de possuir uma superfície regular.

É possível adequar a rampa para deixa-la com inclinação de $8,33 \%$ e inserir um corrimão que obedeça a altura de $0,92 \mathrm{~m}$ determinado pela norma.

De acordo com a NBR 9050/2015, devem ser reservadas vagas para pessoas idosas e com deficiência próximo as entradas e devidamente sinalizadas. 


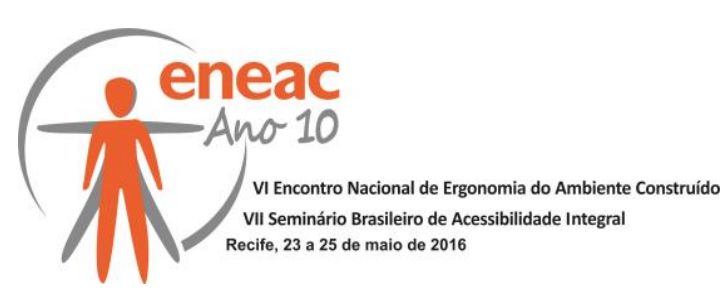

Fonte: Elaborada pelos autores, 2015.

\subsection{Campus IV - Centro De Ciências Aplicadas e Educação (CCAE) - Mamanguape}

A extensão do CCAE que funciona na cidade de Mamanguape oferece os cursos de graduação em Ciência Contáveis, Secretariado, Executivos Bilíngue, Hotelaria, Pedagogia e

Letras distribuídos em edificações recentes que abrigam uma estrutura compostas por salas de aulas, laboratórios, ambientes dos professores, centro de convivência, restaurante universitário, área poliesportiva, residências universitárias e biblioteca. Implantado em um terreno com grande desnível, mas com a maioria das edificações locadas em área plana, o Campus de Mamanguape possui duas entradas, sendo uma no sentido Oeste e o outra no sentido Norte.

O diagnóstico abrangeu a duas entradas e seguiu um trajeto até a área de vivências do Campus, onde está situado o ponto do ônibus que circula dentro da instituição, seguindo o percurso até ao restaurante universitário e, posteriormente, a biblioteca do Campus (Figura 4 tabela 5).

Figura 4 - Planta baixa do Centro De Ciências Aplicadas e Educação com destaque para acesso ao Centro de Vivencias a); acesso ao RU b); calçada de acesso ao Campus c); e acesso à biblioteca d).

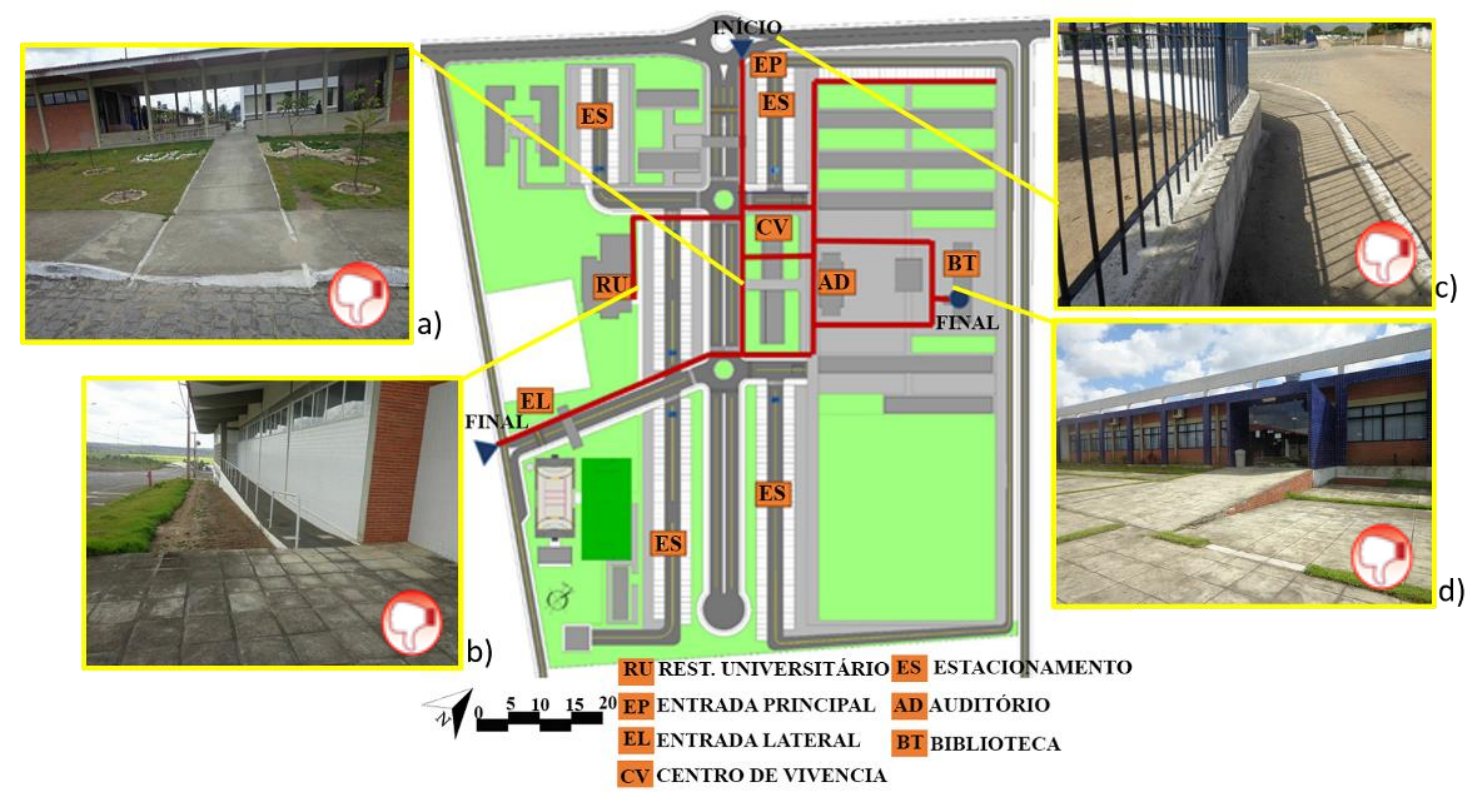

Fonte: Prefeitura Universitária. Editado pelos autores, 2015.

Tabela 5 -situação encontrada no CCAE - Mamanguape

\section{SITUAÇÃO ENCONTRADA}

Rampa de acesso ao centro de vivencia a) - Um dos trajetos possíveis de serem realizados para acessar a biblioteca é pelo centro de vivencia que possui essa rampa com $4,17 \mathrm{~m}$ de largura $e$ $10,27 \%$ de inclinação.

Acesso ao RU b) - Localizado em uma área isolada do campus, onde a calçada não possui

\section{AVALIAÇÃO}

Pare deixar de acordo com a NBR 9050/2015, a rampa deve ter menos de $8,33 \%$

Faz-se necessário deixar o piso regular para 


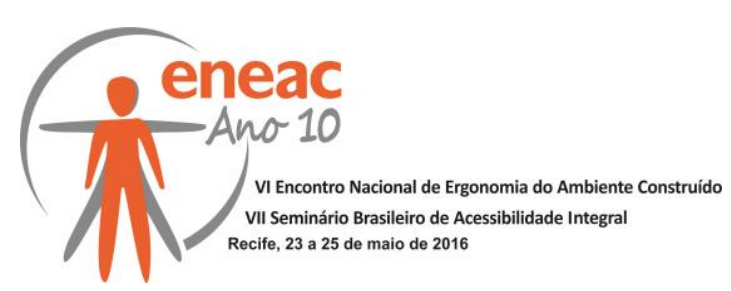

um piso liso e o seu acesso interno é possível por meio de uma rampa com revestimento de borracha antiderrapante, que tem $1,22 \mathrm{~m}$ de largura, inclinação de $5,55 \%$ e corrimão com $0,89 m$.

Calçada de Acesso ao Campus c). Na circulação externa a entrada foi observada que não há guias rebaixadas, sinalização tátil e a calçada possui $1 \mathrm{~m}$ de largura

Rampa de acesso a biblioteca d). A rampa de acesso a biblioteca possui uma inclinação de $5 \%$ dentro dos limites estabelecidos pela NBR 9050, mas o percurso para chegar até ela possui um gramado que entremeia o piso e compromete a regularidade deste em alguns trechos. facilitar o percurso do usuário de cadeira de rodas.

Para tornar acessível a entrada principal da instituição é necessária inserir guia rebaixada, sinalização tátil direcional e de alerta.

O piso não deve ter obstáculos para quem usa cadeira de rodas.

Fonte: Elaborada pelos autores, 2015.

\subsection{Campus V - Centro de Tecnologia e Desenvolvimento Regional (CTDR)}

Centro de Tecnologia e Desenvolvimento Regional, transferido em 2013 para as novas instalações no Bairro de Mangabeira. O Campus V, possui 6 blocos edificados, envolvendo laboratórios, salas de aulas, administrativo, ambiente dos professores e centros acadêmicos no Campus é possível notar que os blocos estão distribuídos em vários níveis vencidos através de rampas e escadas, porém, a maior parte da topografia do local é plana.

No Campus $\mathrm{V}$, o percurso avaliado começou na área externa, no abrigo de ônibus mais próximo ao portão de entrada. Posteriormente, investigamos o percurso da área externa em direção aos blocos de aula. Neste campus, foi necessário avaliar uma rota interna, que, liga os 6 blocos, visto que, a localização da biblioteca e de um pequeno refeitório possuem o acesso único por esse corredor interno (Figura 5, tabela 6).

Figura 5 - Planta baixa do Centro de Tecnologia e Desenvolvimento Regional com enfoque para acesso de pedestres a); vaga especial b); rampa de conexão entre os blocos c); grelha corredor dos blocos d); e rampa no corredor dos blocos e).

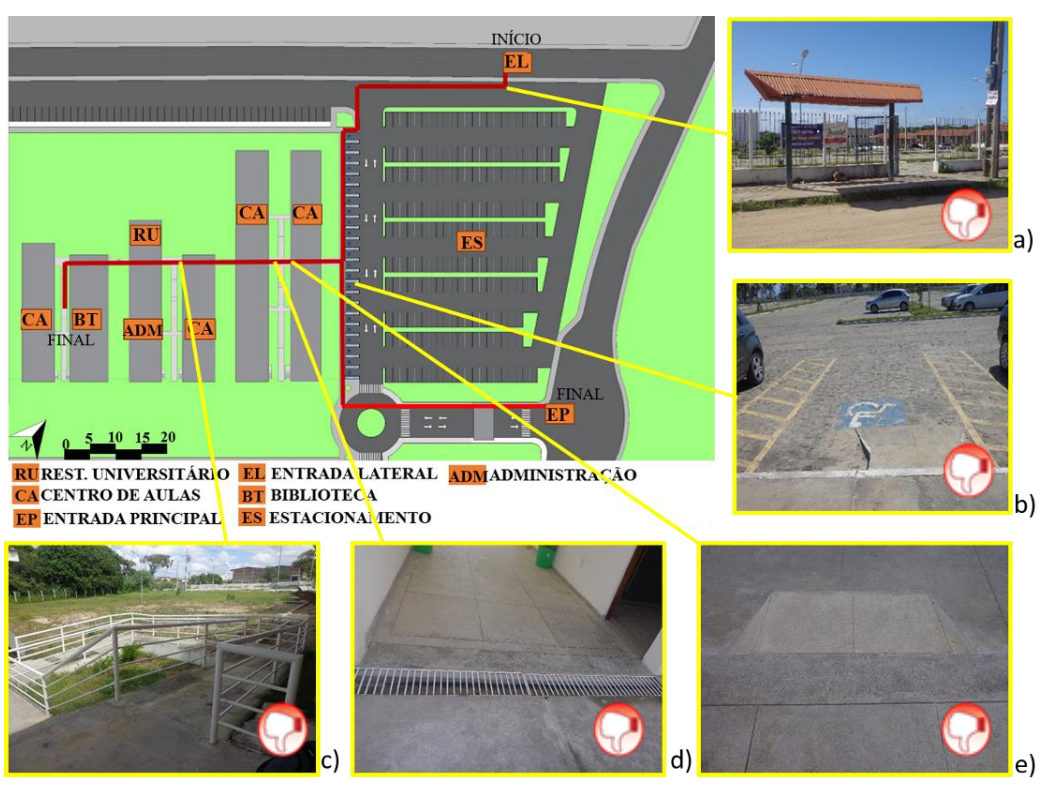




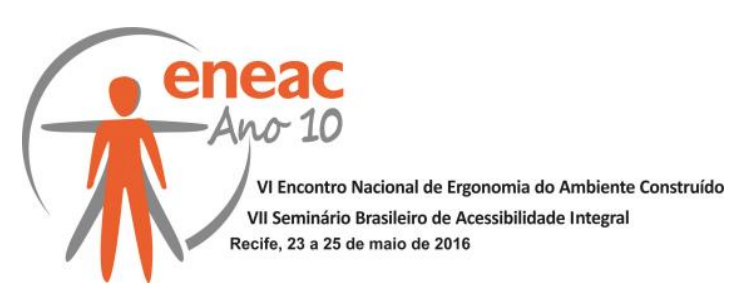

Fonte: Prefeitura Universitária. Editado pelos autores, 2015.

Tabela 6 - situação encontrada no CTDR - Mamanguape

\begin{tabular}{|c|c|}
\hline SITUAÇÃO ENCONTRADA & AVALIAÇÃO \\
\hline $\begin{array}{l}\text { Entrada de pedestres a) - O abrigo de ônibus } \\
\text { existente ocupa a faixa livre da calçada, } \\
\text { configurando-se uma barreira, embora fique } \\
\text { localizado próximo à entrada do Campus destinada } \\
\text { para os pedestres. }\end{array}$ & $\begin{array}{l}\text { Deve-se deixar uma faixa livre de barreiras ou } \\
\text { obstáculos com no mínimo } 0,90 \mathrm{~m} \text { de largura. }\end{array}$ \\
\hline
\end{tabular}

Vaga especial b) - A rampa encontra-se deteriorada e a calçada possui uma superfície firme e regular, mas sem continuidade e sem piso tátil direcional ou de alerta.

O piso da calçada e da rampa deve ser regular e dotada de piso tátil direcional e de alerta

Rampa de acesso aos blocos c) - No corredor dos últimos blocos, há um desnível maior vencido por uma escada e na lateral desta uma rampa dividida em três lances e patamares entre eles, o maior problema desta são as diferentes dimensões do corrimão.

A NBR 9050/2015 determina que os corrimãos devem ser uniformes e com altura máxima de $0,92 \mathrm{~m}$.

Grelha no corredor entre os blocos d) - A presença grelhas posicionados no sentido incorreto, torna-se obstáculo para cadeirantes e cegos correndo o risco de prender a roda da cadeira ou quebrar a bengala.

A norma determina que as grelhas devem ter vãos com dimensão máxima de $15 \mathrm{~mm}$ e instaladas perpendicularmente ao fluxo principal.

Rampa de conexão entre os blocos e) - Entre os blocos há diversos desníveis vencidos por rampas que não se adequam ao previsto pela NBR 9050 .

Todas as rampas devem ser adequadas a NBR 9050/2015 que determinar a inclinação mínima de $8,33 \%$.

Fonte: Elaborada pelos autores, 2015.

Muitos dos problemas encontrados nos cinco campi apresentados, são decorrentes das dificuldades de se construir na Universidade, não se trata apenas de falta de conhecimento das leis e das normas por parte dos profissionais que realizam os projetos. Trata-se de um sistema, onde as dificuldades vão desde conseguir um levantamento topográfico atualizado, passando pela modificação de muitas especificações de materiais descritos nos projetos por materiais de qualidade inferior, até a fase de execução, na qual, a falta de conhecimento dos operários, bem como a inexperiência das construtoras em obras de acessibilidade, também contribui fortemente para os inúmeros problemas que encontramos nos campi da UFPB hoje (COSTA, et al 2014).

\section{CONSIDERAÇÕES FINAIS}

Nesse trabalho, pode se mostrar um pouco da situação ruim em que se encontra alguns campus em relação a acessibilidade, por exemplo o Centro de Ciências Jurídicas localizado em Santa Rita, se encontra com diversos problemas, embora seja uma um conjunto edificado recentemente. O campus $\mathrm{V}$, em Mangabeira, passa pelo mesmo problema, pois embora seja uma edificação relativamente nova, apresenta diversos problemas da ordem de execução e de projeto, fator de certa forma muito preocupante pois só mostra o quão distante estamos do real conceito da acessibilidade. 


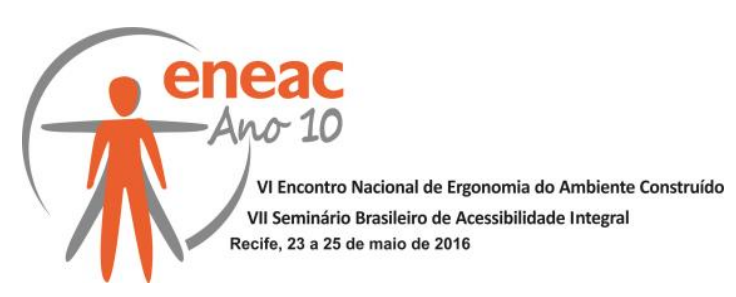

Já o Campus IV dividido entre as cidades de Mamanguape e Rio Tinto, possuem muitos problemas relacionados a ausência da prática de acessibilidade, o CCAE de Mamanguape na rota avaliada não apresenta qualquer adaptação ou solução que leve em consideração os usuários com mobilidade reduzida.

Os campi II e III, em Areia e Bananeiras respectivamente, são por compostos edificações de construção mais antigas e apresentam um terreno com topografia bastante acidentada, além de ambos apresentarem adaptações como rampas, construídas sem levar em consideração o que a NBR 9050: 2015 prediz, possuindo mais pontos críticos em relação aos outros.

A lei $N^{\circ}$ 13. 146, sancionada em 6 de julho de 2015 não trata diretamente da acessibilidade física em instituições públicas, porém ela estabelece que sejam adotadas medidas individualizadas e coletivas em ambientes que maximizem o desenvolvimento acadêmico e social dos estudantes com deficiência, favorecendo o acesso, a permanência, a participação e a aprendizagem em instituições de ensino. Essas medidas, certamente estão ligadas com os aspectos da acessibilidade espacial, visto que se constitui uma necessidade fundamental para aquisição de maior autonomia por pessoas com deficiência.

Observa-se que ainda há um longo caminho a ser percorrido no que diz respeito a acessibilidade nos campi universitários, sobretudo nos estudados, sabendo que construir na Universidade constitui-se um grande desafio, que não requer apenas o conhecimento das normas e leis acerca da acessibilidade. Além disso, é importante destacar que o número de pessoas com deficiência nessas instituições só tende a aumentar, principalmente por causa das políticas de inclusão criadas pelo governo, que procuram tornar viável o acesso de pessoas com deficiência nessas instituições, e tem que garantir, inclusive o acesso físico.

Assim, as universidades têm o dever de se adequarem a uma gama de diferentes usuários e os núcleos de acessibilidade compostos por pesquisadores e estudiosos, precisam trabalhar para promover as soluções relacionadas ao tema dentro dessas instituições.

\section{REFERÊNCIAS BIBLIOGRÁFICAS}

ASSOCIAÇÃO BRASILEIRA DE NORMAS TÉCNICAS - ABNT. NBR 9050/2015: Acessibilidade a edificações, mobiliário, espaços e equipamentos urbanos. Rio de Janeiro, 2015.

BRASIL. A LEI No 13. 146, SANCIONADA EM 6 DE JULHO DE 2015. Estabelece normas gerais e critérios básicos para promoção da acessibilidade das pessoas portadoras de deficiência ou com mobilidade reduzida. 2015.

NEVES, Jose Luís. Pesquisa Qualitativa Características, usos e possibilidades. Caderno de Pesquisa em Administração, São Paulo, v. 1, n. 3, p.0-1, 1996.

REINGHANTZ, Paulo Afonso et al. Observando a qualidade do lugar: Procedimentos para a avaliação pós-ocupação. Rio de Janeiro: Editora, 2008.

SASSAKI, Romeu kazume. Inclusão: construindo uma sociedade para todos. Rio de Janeiro. WVA, 1997.180p.

VERGARA, Lizandra Garcia, et al. Acessibilidade no campus: identificando barreiras arquitetônicas em uma universidade federal do RS. Recife: Eneac, 2009.

COSTA, Angelina Dias Leão. Construção do trecho piloto de rota acessível: a experiência de uma obra de acessibilidade. Rio de Janeiro: Eneac, 2014. 